\title{
Objective physical measures and their association with subjective functional limitations in a representative study population of older Thais
}

\author{
Orawan Prasitsiriphon ${ }^{1,2^{*}}$ (D) and Daniela Weber ${ }^{2,3}$
}

\begin{abstract}
Background: In this study, we analyzed elderly people in Thailand to identify the validity of suggested cutoff points of physical measures, handgrip strength, usual walking speed, and a composite score of both measures to predict functional limitations. Moreover, we examined whether these physical performance measures are accurate indicators of the investigated health outcomes.

Methods: Using Receiver Operating Characteristics (ROC) analysis, we investigated a sample of 8272 respondents aged 60 to 79 years. All data were based on the 2009 National Health Examination Survey (NHES IV) of Thailand.

Results: For males aged 60 to 69 years, handgrip strength was used as an indicator of functional limitations. The cutoff point for disabilities in the activities of daily living (ADLs) was $29.5 \mathrm{~kg}$, while in other limitations it ranged from 28.7 to $31.3 \mathrm{~kg}$. In contrast, usual walking speed was able to indicate ADL disabilities at $0.7 \mathrm{~m}$ per second (m/ s). As one might expect, the cutoff points for males aged 70 to 79 years were lower than for males in the 60 to 69 age group. For females, handgrip strength was able to indicate ADL disabilities at $16.5 \mathrm{~kg}$ for both the 60 to 69 , and 70 to 79 age groups. Likewise, walking speed was indicative of ADL disabilities at $0.6 \mathrm{~m} / \mathrm{s}$ for both age groups. Interestingly, the composite measure increases the ability to detect ADL disabilities in the younger group but not in the older group. The area under the curve (AUC) of cutoffs measuring the detection power of a diagnostic test was varied, ranging from 0.535 to 0.7386 .

Conclusions: The cutoff points of three measures varied according to sex and type of functional limitations. Our findings also showed that physical performance measures were useful for identifying people with an increased risk of functional limitations, particularly for ADL disabilities. However, although the AUC of the cutoffs of other functional limitations were relatively low, they should be considered with caution.
\end{abstract}

Keywords: Handgrip strength, Usual walking speed, Functional limitations, ADL disabilities, ROC analysis

\section{Background}

The global trend of an increasing number of elderly people in the population is also observed in Thailand. Research shows that around $40 \%$ of elderly Thais experience at least one functional limitation in their daily

\footnotetext{
* Correspondence: orawan.pr@student.chula.ac.th; oprasitsiriphon@gmail.com ${ }^{1}$ College of Population Studies, Chulalongkorn University, Bangkok 10330, Thailand

${ }^{2}$ Wittgenstein Centre for Demography and Global Human Capital (IIASA, VID/ OEAW, WU), International Institute for Applied Systems Analysis (IIASA), 2361 Laxenburg, Austria

Full list of author information is available at the end of the article
}

activities and that limitations increase with age [1]. Care of the elderly population thus poses growing challenges for the individual, their families, and the government in Thailand.

Handgrip strength (HGS) and usual walking speed (UWS) are objective measures of overall muscle strength and physical function. Therefore, HGS and UWS are also included in most of the diagnostic criteria of sarcopenia characterized by the presence of low muscle mass and low muscle strength [2]. HGS and UWS are used to measure the particular physical abilities needed to

(C) The Author(s). 2019 Open Access This article is distributed under the terms of the Creative Commons Attribution 4.0 International License (http://creativecommons.org/licenses/by/4.0/), which permits unrestricted use, distribution, and 
accomplish common daily activities [3-6]. Many studies in community and clinical settings revealed an association between low HGS and a higher risk of mortality $[3,4,7-12]$ and disability $[5,10]$. Slow walking speed has also been associated with a greater risk of mortality $[4,6,13-15]$, disability, subsequent nursing home admission [13, 14, 16], and cognitive problems [17].

Recent research in the field of geriatrics has attempted to identify people at high risk for functional limitations or frailty (i.e elevated decline in physiologic reserve and function) by determining thresholds for objective muscle-strength measurements (i.e., HGS, UWS). Although previous studies [18] indicate some consensus on cutoff values, these values are dependent on the availability of reference studies. The thresholds most frequently used to identify people with i) slow WS and sarcopenia or ii) frailty were $0.8 \mathrm{~m} / \mathrm{s}$ [2] and 0.8 to $0.9 \mathrm{~m} / \mathrm{s}$ $[2,19]$ respectively. Likewise, cutoff points to identify people with i) low HGS and sarcopenia or ii) specific disabilities were identified at 32 to $35 \mathrm{~kg}$ and 21 to $22 \mathrm{~kg}$ for males and females respectively, in Europe, America, Turkey, and some regions of Finland [20-23]. Moreover, a few studies reported cutoff values in HGS related to a specific disability [20, 24, 25]. However, these values could be different for Thais, given the differences in their physique compared with Europeans.

Several studies have shown the power of physical performance measures or composite scores to differentiate variations in functional limitations. For instance, Sieno et al. $[26,27]$ suggested that as a single performance measurement, UWS and HGS tests had comparable power to assess disability [27]. In another study on older women [26], UWS was found to be a better marker of poor mobility than a lower-extremity performance test comprising HGS, manipulating pegs in a pegboard, and functional reach. In terms of its power to detect disabilities in the activities of daily living (ADLs), UWS was as good a marker as the overall function measure derived from lower-extremity strength (tandem stance, chair stand test, alternate step, and get-up and go) and upper-extremity strength. This finding held despite a 3 to $5 \%$ difference between the areas under the receiver operating characteristic (ROC) curves of UWS and overall function. Guralnik et al. [28] also revealed that for predicting ADL and mobility disabilities in community-dwelling (non-institutionalized) populations, the UWS alone was nearly as good as the overall function (created by summing the test scores for standing balance, usual walking speed, and rising five times from a chair), having a 3 to $5 \%$ range of difference in areas under the curve (AUCs).

The objective of this study is to identify the validity of suggested cutoff points of physical measures (e.g., HGS, UWS, and a composite score of both measures) to project the increased likelihood of functional limitations. Using data from the 2009 National Health Examination Surveys of Thailand (NHES IV), we also investigated whether a combination of HGS and UWS can more accurately detect functional limitations in older Thais than each physical measure taken alone. As well as identifying the cutoff points for older Thai adults, this study aims to present their implications for development interventions and healthcare policies, given that cutoff points offer a simple and accurate way to identify older people at risk of disabilities.

\section{Methods}

\section{Data and study population}

The study population was drawn from the 2009 National Health Examination Survey of Thailand (NHES IV), which was the first study in Thailand to examine objective measures of mobility at a national level. A four-stage stratified probability sampling method was used to yield a nationally and regionally representative sample of the non-institutionalized population. Ultimately, a sample of 39,290 participants over the age of 15 from Bangkok and 20 provinces nationwide was obtained. The NHES IV was approved by the Ethical Review Committee for Research in Human Subjects of the Ministry of Public Health, and all participants provided written informed consent.

The sample was controlled as follows: i) the sample population was restricted to respondents aged 60 to 79 years; ii) respondents completed at least one of the physical performance tests; and iii) respondents completed the questionnaire on self-reported outcome measures, namely, Activities of Daily Living (ADLs) and Instrumental Activities of Daily Living (IADLs), upper-body limitations, lower-body limitations, and higher functional limitations. After applying these controls, 8272 respondents remained in our sample. We further excluded outliers such as those with the ability to walk $4 \mathrm{~m}$ in under $0.5 \mathrm{~s}$ (37 people). An overview of the final sample size by physical performance and self-reported outcome measurements is provided separately for males and females in Table 1.

\section{Measurements \\ Self-reported health outcome measurements}

Activities of daily living (ADL) A modified version of the Katz ADL scale with 6 items was included in the questionnaire [29]. When a participant reported at least one difficulty in basic self-care activities without assistance, including eating and drinking, dressing, bathing, using the toilet, walking across a room, and transferring from beds or chairs, the variable ADL was coded with a 1 , or with a 0 if no difficulty was reported. 
Instrumental activities of daily living (IADL) Participants needing help with at least one instrumental activity, including using the telephone, handling money, managing medication, using transportation or driving, and housekeeping [30], were identified as having limitations in terms of performing IADLs.

Upper-body limitations Respondents unable to carry heavy objects without assistance were defined as having upper-body limitations.

Lower-body limitations Respondents unable either to walk at least $400 \mathrm{~m}$ without resting or to go up/down a flight of 10 stairs without resting were defined as having lower-body limitations.

Higher functional limitations Respondents who were unable to perform at least two of the activities unassisted, such as cutting toenails, heavy housework, carrying heavy objects, and walking at least $400 \mathrm{~m}$ without resting were defined as having higher functional limitations.

\section{Physical variables}

Handgrip strength (HGS) HGS was measured in kilograms $(\mathrm{kg})$ using a handgrip dynamometer, Grip-D T.K.K.5401. Respondents were instructed to sit with the elbow at a $90^{\circ}$ angle with the wrist in a neutral position, keeping the upper arm tight against the trunk, and the inner lever of the dynamometer adjusted to fit the hand. Before the test, the respondents were asked if they had experienced any problems from recent surgery, injury, or other conditions of either the left or right hand within the last three months. Respondents willing to do the test and reporting no hand problems were asked to squeeze the dynamometer as hard as possible for a few seconds. Two maximum measures were recorded for each hand. The maximum HGS measure was used for this analysis.

Usual walking speed (UWS) Survey participants aged at least 60 who were willing and able to do the timed walk test (walking aids were permitted), were asked to walk $4 \mathrm{~m}$ at their usual pace. The time to walk $4 \mathrm{~m}$ was recorded in seconds-in our study we measured walking speed in meters per second $(\mathrm{m} / \mathrm{s})$.

Overall function A composite score of muscle strength and physical performance was constructed based on HGS and UWS. As the measurements for each test were recorded in different units, we applied sex-specific standardization with a mean of 10 and calculated a sum score.

\section{Demographic variables}

The demographic characteristics included age, gender (male/female), body weight, body height, education, and geographic location of residence. Age corresponded to the date of birth stated on an identity card. Body weight and height were measured following a standardized protocol as a component of the physical performance measures of the NHES IV. Education was categorized into eight levels: no education, primary school, junior high school, senior high school, vocational certificate/ diploma, bachelor's degree or higher, temple education, and others. We recoded the variable education into three levels for this study: no education, primary school, and at least secondary school. The geographic area variable indicated the location of the respondent's residence, distinguishing five regions (i.e., Bangkok, North-, Central-, Northeast-, and South Thailand). All these demographic variables were included in the analysis as potential confounders.

\section{Health variables}

Health variables included cognitive impairment, diabetes, and hypertension, based on clinical diagnosis and self-reporting. Respondents had a blood test to determine their fasting plasma glucose (FPG), and if this was $126 \mathrm{mg} / \mathrm{dl}$ and above, the person was diagnosed with diabetes. Self-reported diabetes was determined with the question, "Has a doctor diagnosed you with this problem?" Trained physicians following a standard protocol measured respondents' blood pressure three times using an automatic blood pressure monitor. An average of the last two brachial systolic and diastolic blood pressure readings was used for systolic and diastolic blood pressure values, if the first test gave unusually high values. Respondents were defined as having hypertension if i) they had a systolic blood pressure of $140 \mathrm{mmHg}$ and above, or a diastolic pressure of $90 \mathrm{mmHg}$ and above, or ii) if they were taking medication to reduce their blood pressure. Cognitive impairment was indicated following the approach used by Langa et al. [31], in which a composite score using different information from self-reported respondents was used. Specifically, we used the assessment of difficulty in two questions about memory (concentration and new learning) ranging from excellent to poor (score 1-5) and the assessment of limitations in five IADLs: managing money, taking medication, preparing hot meals, using phones, and shopping for groceries. Responses were coded according to a four-point scale where $1=$ cannot, $2=$ with help, $3=$ can do, and $4=$ never done before. We excluded the participants who reported never having done at least one instrumental activity before in 5 IADLs $(n=2433)$. Using this information, we classified respondents as cognitively impaired if 
they were unable to do or needed help with at least one instrumental activity in 5 IADLs and had difficulties or some difficulties with at least one memory question. Cronbach's alpha for this cognitive impairment is $58 \%$. These health variables were also considered as potential confounders within the analysis.

\section{Statistics}

First, we used descriptive statistics to characterize the study participants. We then calculated sensitivity, specificity, and the AUC of the ROC curve analysis for each physical measurement (i.e., HGS and UWS) and overall function to identify the optimal cutoff values. The optimum cutoff values of each of the three physical measurements to predict the five health outcomes (i.e., ADL disabilities, IADL disabilities, upper-body limitations, lower-body limitations, and higher functional limitations) were estimated by the minimum value of (1-sensitivity $)^{2}+(1 \text {-specificity })^{2}$ [32]. The predictive performance of the optimum cutoff values used the Delong method [33], which was implemented in the statistical software, STATA. The AUC value, statistic, and 95\% confidence interval were reported to indicate how well each physical measure performed at detecting the health outcomes [34]. Moreover, logistic regressions were used to establish the strength of each of the optimal cutoff values associated with their outcomes and adjusting for potential confounders [35]. All analyses were run separately by gender (male and female) and also by age groups (60 to 69 and 70 to 79 year olds) to avoid aging effects on the five body limitations. For instance, the younger older persons in particular, could have an effect on the detected power in ADL and IADL. The sampling weights were used to make the results representative of the older Thai population. All analyses used STATA Statistical Software Release 13.

\section{Results}

\section{Characteristics of samples}

The sample was divided into two age groups 60 to 69 (the younger group) and 70 to 79 years (the older group) for men and women separately. The results of the characteristics were shown in the additional data (Table 1).

In men, the average age was 64.2 years for the younger, and 73.9 years for the older age group. About $5.5 \%$ of the males in the 60 to 69 age group reported cognitive impairment, $13.6 \%$ reported diabetes, and $43.1 \%$ reported hypertension, whereas $9.1 \%$ of the older males reported cognitive impairment, $14.3 \%$ diabetes, and 51.3\% hypertension. Further, the 60 to 69 age group had an average HGS of $31.5 \mathrm{~kg}$, UWS of $0.8 \mathrm{~m} / \mathrm{s}$, and a score of 4.5 in average overall function. Their older counterparts had an average HGS of $26.5 \mathrm{~kg}$, UWS of $0.7 \mathrm{~m} / \mathrm{s}$ and overall function of 3.8. Functional limitations affected ADL disabilities, IADL disabilities, upper-body limitations, lower-body limitations, and higher functional limitations by $1.2,32.9,11.1,13.2$, and $7.9 \%$ respectively in the younger age group, and by $3.7,52.8,23.7,26.2$, and $20.3 \%$ respectively in the older age group.

In women, the mean age of the younger population was 64.1 years, and 73.9 years for the older female population. The younger female group had lower strength in HGS and UWS than males $(21.0 \mathrm{~kg}$, and $0.7 \mathrm{~m} / \mathrm{s}$, respectively), while the older female group had a HGS of $18.3 \mathrm{~kg}$ and UWS of $0.6 \mathrm{~m} / \mathrm{s}$. Both groups of women reported a greater prevalence of cognitive impairment, diabetes, and hypertension than men. The younger females reported $11.2 \%$ cognitive impairment, $19.2 \%$ diabetes, 45\% hypertension, 1.4\% ADL disabilities, 56\% IADL disabilities, $24.6 \%$ upper-body limitations, 34\% lower-body limitations, and $22.6 \%$ higher functional limitations. As expected, the older group had a higher prevalence of diseases or limitations (17.2\% cognitive impairment, $17.1 \%$ diabetes, 52.5\% hypertension, 3\% ADL disabilities, 81.3\% IADL disabilities, $46.8 \%$ upper-body limitations, $54 \%$ lower-body limitations, and $42.6 \%$ higher functional limitations) than the younger group.

Physical strength decreases with increasing age and overall, women have lower physical performance than men. By age groups and sex, age groups reporting any conditions of ADL disabilities, IADL disabilities, upper-body limitations, lower-body limitations, and higher functional limitations tend to have lower mean scores in all three physical performances. Respondents with ADL disabilities were likely to be the weakest compared to those with other functional restrictions.

\section{Cutoff points for HGS, UWS, and overall function Males}

The ability of physical performance tests to accurately differentiate between elderly people with and without functional limitations in each domain is reflected by the AUC of the ROC curve analysis for men presented in Table 2. Based on the results, HGS for predicting ADL disabilities shows moderate accuracy in males aged 60 to 69 (AUC $=0.74)$ and low accuracy in males aged 70 to 79 (AUC $=0.69$ ), as well as low accuracy for IADL disabilities, upper-body limitations, lower-body limitations, and higher functional limitations in both age groups (AUC $=0.61$ to 0.66). Moreover, the optimal cutoff values for men's ADL disabilities were not much different from the other outcomes except for IADL disabilities with the highest optimal cutoff values. ADL disabilities were $29.5 \mathrm{~kg}$ for 60 to 69 year olds and $25.3 \mathrm{~kg}$ for 70 to 79 year olds, while IADL disabilities were $31.3 \mathrm{~kg}$ for 60 to 69 year olds and $26.4 \mathrm{~kg}$ for 70 to 79 year olds. 
Table 1 Descriptive overview with characteristic details for each variable by age-group and gender

\begin{tabular}{|c|c|c|c|c|c|c|c|c|}
\hline & \multicolumn{4}{|l|}{ Male } & \multicolumn{4}{|c|}{ Female } \\
\hline & \multicolumn{2}{|c|}{ 60-69 years } & \multicolumn{2}{|c|}{ 70-79 years } & \multicolumn{2}{|c|}{ 60-69 years } & \multicolumn{2}{|c|}{ 70-79 years } \\
\hline & $\mathrm{N}$ & $\begin{array}{l}\text { Mean }(95 \% \mathrm{Cl}) / \\
\text { \%Share }\end{array}$ & $\mathrm{N}$ & $\begin{array}{l}\text { Mean }(95 \% \mathrm{Cl}) / \\
\text { \%Share }\end{array}$ & $\mathrm{N}$ & $\begin{array}{l}\text { Mean }(95 \% \mathrm{Cl}) / \\
\text { \%Share }\end{array}$ & $\bar{M}$ & $\begin{array}{l}\text { Mean }(95 \% \mathrm{Cl}) / \\
\text { \%Share }\end{array}$ \\
\hline Age & 2498 & $\begin{array}{l}64.2 \\
(58.6-69.9)\end{array}$ & 1566 & $\begin{array}{l}73.9 \\
(68.6-79.3)\end{array}$ & 2559 & $\begin{array}{l}64.1 \\
(58.4-69.7)\end{array}$ & 1652 & $\begin{array}{l}73.9 \\
(68.4-79.3)\end{array}$ \\
\hline Weight & 2487 & $\begin{array}{l}60.3 \\
(37.7-82.9)\end{array}$ & 1557 & $\begin{array}{l}56.3 \\
(34.4-78.2)\end{array}$ & 2552 & $\begin{array}{l}56.1 \\
(33.5-78.8)\end{array}$ & 1645 & $\begin{array}{l}51.1 \\
(29.5-72.8)\end{array}$ \\
\hline Height & 2487 & $\begin{array}{l}162.2 \\
(150.3-174.1)\end{array}$ & 1552 & $\begin{array}{l}160.3 \\
(147.8-172.8)\end{array}$ & 2544 & $\begin{array}{l}151.4 \\
(141.1-161.7)\end{array}$ & 1619 & $\begin{array}{l}149.5 \\
(138.5-160.4)\end{array}$ \\
\hline \% Education level & 2494 & & 1559 & & 2556 & & 1650 & \\
\hline No education & & 4.4 & & 7.9 & & 12.2 & & 20 \\
\hline Primary school & & 78.1 & & 80.6 & & 79.7 & & 76.5 \\
\hline At least secondary school & & 17.5 & & 11.5 & & 8.1 & & 3.5 \\
\hline$\%$ Region & 2498 & & 1566 & & 2559 & & 1652 & \\
\hline Bangkok & & 11.2 & & 16.5 & & 11.2 & & 10.1 \\
\hline North & & 19.7 & & 19.3 & & 18.6 & & 20 \\
\hline Central & & 24.5 & & 23.9 & & 26 & & 24.8 \\
\hline Northeast & & 32.7 & & 27.1 & & 32.9 & & 31.3 \\
\hline South & & 11.9 & & 13.1 & & 11.3 & & 13.8 \\
\hline$\%$ Cognitive impairment & 2490 & & 1430 & & 2382 & & 1399 & \\
\hline - No & & 94.5 & & 90.9 & & 88.8 & & 82.8 \\
\hline - Yes & & 5.5 & & 9.1 & & 11.2 & & 17.2 \\
\hline \% Diabetes & 2408 & & 1508 & & 2479 & & 1597 & \\
\hline - No & & 86.4 & & 85.7 & & 80.8 & & 82.9 \\
\hline - Yes & & 13.6 & & 14.3 & & 19.2 & & 17.1 \\
\hline \% Hypertension & 2489 & & 1565 & & 2554 & & 1652 & \\
\hline - No & & 56.9 & & 48.7 & & 55 & & 47.5 \\
\hline - Yes & & 43.1 & & 51.3 & & 45 & & 52.5 \\
\hline \multicolumn{9}{|l|}{ Physical performances } \\
\hline HGS (kilograms) & 2489 & $\begin{array}{l}31.5 \\
(18.4-44.5)\end{array}$ & 1561 & $\begin{array}{l}26.5 \\
(13.7-39.3)\end{array}$ & 2550 & $\begin{array}{l}21.0 \\
(12.3-29.8)\end{array}$ & 1645 & $\begin{array}{l}18.3 \\
(10.2-26.4)\end{array}$ \\
\hline UWS (m/s) & 2453 & $\begin{array}{l}0.8 \\
(0.4-1.2)\end{array}$ & 1530 & $\begin{array}{l}0.7 \\
(0.3-1.1)\end{array}$ & 2509 & $\begin{array}{l}0.7 \\
(0.4-1.0)\end{array}$ & 1607 & $\begin{array}{l}0.6 \\
(0.3-1.0)\end{array}$ \\
\hline Overall function & 2453 & $\begin{array}{l}4.5 \\
(2.7-6.3)\end{array}$ & 1528 & $\begin{array}{l}3.8 \\
(1.8-5.7)\end{array}$ & 2504 & $\begin{array}{l}4.0 \\
(2.3-5.7)\end{array}$ & 1604 & $\begin{array}{l}3.4 \\
(1.7-5.0)\end{array}$ \\
\hline \multicolumn{9}{|l|}{ Outcome } \\
\hline$\%$ ADL disabilities & 2471 & & 1547 & & 2533 & & 1641 & \\
\hline - No & & 98.8 & & 96.3 & & 98.6 & & 97 \\
\hline - Yes & & 1.2 & & 3.7 & & 1.4 & & 3 \\
\hline$\%$ IADL disabilities & 2001 & & 1163 & & 2088 & & 1275 & \\
\hline - No & & 67.1 & & 47.2 & & 44 & & 18.7 \\
\hline - Yes & & 32.9 & & 52.8 & & 56 & & 81.3 \\
\hline \% Upper-body limitations & 2348 & & 1430 & & 2385 & & 1428 & \\
\hline - No & & 88.9 & & 76.3 & & 75.4 & & 53.2 \\
\hline - Yes & & 11.1 & & 23.7 & & 24.6 & & 46.8 \\
\hline$\%$ Lower-body limitations & 2291 & & 1423 & & 2264 & & 1405 & \\
\hline - No & & 86.8 & & 73.8 & & 66 & & 46 \\
\hline
\end{tabular}


Table 1 Descriptive overview with characteristic details for each variable by age-group and gender (Continued)

\begin{tabular}{|c|c|c|c|c|c|c|c|c|}
\hline & \multicolumn{4}{|l|}{ Male } & \multicolumn{4}{|c|}{ Female } \\
\hline & \multicolumn{2}{|c|}{ 60-69 years } & \multicolumn{2}{|c|}{ 70-79years } & \multicolumn{2}{|c|}{ 60-69 years } & \multicolumn{2}{|c|}{ 70-79 years } \\
\hline & $\mathrm{N}$ & $\begin{array}{l}\text { Mean }(95 \% \mathrm{Cl}) / \\
\text { \%Share }\end{array}$ & $\mathrm{N}$ & $\begin{array}{l}\text { Mean }(95 \% \mathrm{Cl}) / \\
\text { \%Share }\end{array}$ & $\mathrm{N}$ & $\begin{array}{l}\text { Mean }(95 \% \mathrm{Cl}) / \\
\text { \%Share }\end{array}$ & $\mathrm{M}$ & $\begin{array}{l}\text { Mean }(95 \% \mathrm{Cl}) / \\
\text { \%Share }\end{array}$ \\
\hline - Yes & & 13.2 & & 26.2 & & 34 & & 54 \\
\hline$\%$ Higher functioning limitations & 2101 & & 1244 & & 2091 & & 1186 & \\
\hline - No & & 92.1 & & 79.7 & & 77.4 & & 57.4 \\
\hline - Yes & & 7.9 & & 20.3 & & 22.6 & & 42.6 \\
\hline
\end{tabular}

95\% CI 95\% confidence interval, HGS handgrip strength, UWS usual walking speed, $A D L$ activities of daily living, IADL instrumental activities of daily living

Using UWS as an indicator enabled us to differentiate between males with and without ADL disabilities with moderate accuracy for younger participants $(\mathrm{AUC}=0.72)$ and good accuracy for older males $(\mathrm{AUC}=0.80)$. Interestingly, it was not possible to discriminate between elderly people with and without functional limitations in the other outcomes except in terms of IADL disabilities and lower-body limitations in the older group. Furthermore, the optimal cutoff values for men's ADL disabilities were lower than for the other outcomes. ADL disabilities were $0.7 \mathrm{~m} / \mathrm{s}$ for the 60 to 69 age group and $0.6 \mathrm{~m} / \mathrm{s}$ for the 70 to 79 age group, while the other outcomes ranged between 0.8 and $0.9 \mathrm{~m} / \mathrm{s}$ for the younger groups, and between 0.7 and $0.8 \mathrm{~m} / \mathrm{s}$ for the older groups.

The ability to accurately differentiate in terms of overall function was good for ADL disability $(\mathrm{AUC}=0.86$ ) and low for the other outcomes (AUC $=0.61$ to 0.63 ) in males aged 60 to 69 years. In the older group, it also shows good accuracy in predicting ADL disabilities (AUC $=0.80$ ), while accuracy for the other outcomes is low (AUC $=0.65$ to 0.67 ). The optimal scores vary for all outcomes: in ADL disabilities, 3.5 for 60 to 69 year olds, 2.9 for 70 to 79 year olds, and in other outcomes, respectively 4.2 to 4.3 and 3.5 to 3.7 .

\section{Females}

The ability of physical performance tests to accurately project women's health outcomes is presented in Table 3. HGS shows moderate $(\mathrm{AUC}=0.72$ ) and low accuracy (AUC $=0.67)$ for predicting ADL disabilities in both the younger and older group. HGS fails to detect the other health outcomes $(\mathrm{AUC}<0.6)$ in both age groups. The optimal cutoff values for ADL disabilities are $16.5 \mathrm{~kg}$ for both the 60 to 69 age group and the 70 to 79 age group. The cutoff ranges for the other outcomes are 20.8 to $21.5 \mathrm{~kg}$ in younger females and 18.5 to $19.2 \mathrm{~kg}$ in older females.

By using UWS as a measure, we were able to detect females aged 60 to 69 years with and without ADL disabilities (AUC $=0.69$ ), as well as lower-body limitations $(\mathrm{AUC}=0.60)$ and higher functional limitations $(\mathrm{AUC}=$ 60). UWS also differentiates for ADL disabilities in the older group with moderate accuracy $(\mathrm{AUC}=0.71)$. The cutoff values of UWS in identifying IADL disabilities and upper-body limitations failed (AUC $=0.55-0.59$ ). The cutoff points of UWS in 60 to 69 year olds were 0.6 $\mathrm{m} / \mathrm{s}$ for ADL disabilities, $0.8 \mathrm{~m} / \mathrm{s}$ for IADL disabilities, and $0.7 \mathrm{~m} / \mathrm{s}$ for others. For the older group, the cutoff points were $0.6 \mathrm{~m} / \mathrm{s}$ for ADL disabilities and $0.9 \mathrm{~m} / \mathrm{s}$ for the other outcomes.

Overall function shows similar results to those of HGS and has a moderate accuracy in predicting ADL disabilities among both younger $(\mathrm{AUC}=0.74)$ and older females $(A U C=0.70)$, but it failed to accurately predict the other outcomes. The optimal cutoff rate in overall function is 3.2 for 60 to 69 year olds and 3.0 for 70 to 79 year olds. The other outcomes range between 3.7 and 4.2 for the younger group, and between 3.4 and 3.5 for the older one.

The ROC curves of the handgrip strength, usual walking speed and overall function to detect ADL disability, IADL disability, upper-body functions, lower-body functions and higher functional limitations among Thai elderly people by age groups and sexes are shown in Additional file 1: Figures S1-S5.

\section{Associations between HGS, UWS, and overall function,} and the prevalence of five functional limitations

The results of the investigation of the relationship between good physical performance, which was identified by the previously defined cutoff values, and health outcomes for men and women are presented in Table 3. There are many significant associations between the three physical performance measurements (HGS, UWS, and overall function) and the health outcomes for both age groups. For both sexes and both age groups, the adjusted-odds ratios of physical tests to ADL disabilities were higher than in other functional restrictions. These results remained stable following the addition of potential confounders such as education, region of residence, cognitive impairment, diabetes, and hypertension. However, we found that UWS is not significant for IADL disabilities in the two male groups (models 1 to 3). In the younger and older female population, there was a 
Table 2 Cutoff value of HGS, UWS, and overall function with self-reported ADL disabilities, IADL disabilities, upper-body limitations, lower-body limitations, and higher functional limitations by gender

\begin{tabular}{|c|c|c|c|c|c|c|c|c|}
\hline & \multicolumn{4}{|l|}{ Male } & \multicolumn{4}{|c|}{ Female } \\
\hline & $\mathrm{CP}$ & Sn & $\mathrm{Sp}$ & AUC (95\%Cl) & $\overline{C P}$ & $\mathrm{Sn}$ & Sp & AUC (95\%Cl) \\
\hline \multicolumn{9}{|l|}{ Handgrip strength } \\
\hline \multicolumn{9}{|l|}{$60-69$ years } \\
\hline ADL disabilities & 29.5 & 0.87 & 0.61 & $\begin{array}{l}0.74 \\
(0.740-0.744)\end{array}$ & 16.5 & 0.59 & 0.85 & $\begin{array}{l}0.72 \\
(0.714-0.720)\end{array}$ \\
\hline IADL disabilities & 31.3 & 0.63 & 0.60 & $\begin{array}{l}0.62 \\
(0.616-0.618)\end{array}$ & 21.5 & 0.58 & 0.55 & $0.57(0.566-0.567)$ \\
\hline Upper-body limitations & 28.7 & 0.58 & 0.70 & $\begin{array}{l}0.64 \\
(0.634-0.637)\end{array}$ & 20.8 & 0.56 & 0.55 & $\begin{array}{l}0.55 \\
(0.553-0.554)\end{array}$ \\
\hline Lower-body limitations & 30.0 & 0.61 & 0.62 & $\begin{array}{l}0.62 \\
(0.616-0.618)\end{array}$ & 20.8 & 0.58 & 0.58 & $\begin{array}{l}0.58 \\
(0.576-0.578)\end{array}$ \\
\hline Higher functional limitations & 30.0 & 0.59 & 0.62 & $\begin{array}{l}0.61 \\
(0.605-0.608)\end{array}$ & 20.8 & 0.57 & 0.55 & $\begin{array}{l}0.56 \\
(0.56-0.564)\end{array}$ \\
\hline \multicolumn{9}{|l|}{ 70-79 years } \\
\hline ADL disabilities & 25.3 & 0.80 & 0.57 & $\begin{array}{l}0.69 \\
(0.685-0.689)\end{array}$ & 16.5 & 0.65 & 0.69 & $\begin{array}{l}0.67 \\
(0.665-0.670)\end{array}$ \\
\hline IADL disabilities & 26.4 & 0.64 & 0.64 & $\begin{array}{l}0.64 \\
(0.636-0.638)\end{array}$ & 19.2 & 0.61 & 0.57 & $\begin{array}{l}0.59 \\
(0.591-0.593)\end{array}$ \\
\hline Upper-body limitations & 25.4 & 0.64 & 0.62 & $\begin{array}{l}0.63 \\
(0.632-0.634)\end{array}$ & 19.1 & 0.65 & 0.50 & $\begin{array}{l}0.58 \\
(0.577-0.579)\end{array}$ \\
\hline Lower-body limitations & 25.5 & 0.63 & 0.63 & $\begin{array}{l}0.63 \\
(0.626-0.628)\end{array}$ & 18.5 & 0.56 & 0.59 & $\begin{array}{l}0.57 \\
(0.573-0.575)\end{array}$ \\
\hline Higher functional limitations & 25.4 & 0.67 & 0.64 & $\begin{array}{l}0.66 \\
(0.655-0.658)\end{array}$ & 19.1 & 0.65 & 0.52 & $\begin{array}{l}0.59 \\
(0.584-0.586)\end{array}$ \\
\hline \multicolumn{9}{|l|}{ Usual walking speed } \\
\hline \multicolumn{9}{|l|}{$60-69$ years } \\
\hline ADL disabilities & 0.7 & 0.84 & 0.59 & $\begin{array}{l}0.72 \\
(0.713-0.720)\end{array}$ & 0.6 & 0.56 & 0.82 & $\begin{array}{l}0.69 \\
(0.687-0.694)\end{array}$ \\
\hline IADL disabilities & 0.9 & 0.84 & 0.23 & $\begin{array}{l}0.53 \\
(0.531-0.532)\end{array}$ & 0.8 & 0.68 & 0.47 & $\begin{array}{l}0.58 \\
(0.574-0.575)\end{array}$ \\
\hline Upper-body limitations & 0.8 & 0.54 & 0.60 & $\begin{array}{l}0.57 \\
(0.570-0.573)\end{array}$ & 0.7 & 0.76 & 0.43 & $\begin{array}{l}0.59 \\
(0.590-0.591)\end{array}$ \\
\hline Lower-body limitations & 0.8 & 0.57 & 0.61 & $\begin{array}{l}0.59 \\
(0.592-0.594)\end{array}$ & 0.7 & 0.76 & 0.45 & $\begin{array}{l}0.60 \\
(0.603-0.604)\end{array}$ \\
\hline Higher functional limitations & 0.8 & 0.56 & 0.60 & $\begin{array}{l}0.58 \\
(0.578-0.581)\end{array}$ & 0.7 & 0.78 & 0.43 & $\begin{array}{l}0.60 \\
(0.600-0.602)\end{array}$ \\
\hline \multicolumn{9}{|l|}{ 70-79years } \\
\hline ADL disabilities & 0.6 & 0.80 & 0.79 & $\begin{array}{l}0.80 \\
(0.796-0.801)\end{array}$ & 0.6 & 0.76 & 0.67 & $\begin{array}{l}0.71 \\
(0.712-0.717)\end{array}$ \\
\hline IADL disabilities & 0.8 & 0.68 & 0.47 & $\begin{array}{l}0.58 \\
(0.576-0.578)\end{array}$ & 0.7 & 0.83 & 0.29 & $\begin{array}{l}0.56 \\
(0.558-0.560)\end{array}$ \\
\hline Upper-body limitations & 0.7 & 0.78 & 0.46 & $\begin{array}{l}0.62 \\
(0.617-0.619)\end{array}$ & 0.7 & 0.84 & 0.26 & $\begin{array}{l}0.55 \\
(0.549-0.550)\end{array}$ \\
\hline Lower-body limitations & 0.7 & 0.72 & 0.45 & $\begin{array}{l}0.58 \\
(0.581-0.583)\end{array}$ & 0.7 & 0.83 & 0.25 & $\begin{array}{l}0.54 \\
(0.540-0.541)\end{array}$ \\
\hline Higher functional limitations & 0.7 & 0.79 & 0.46 & $\begin{array}{l}0.63 \\
(0.627-0.629)\end{array}$ & 0.7 & 0.84 & 0.25 & $\begin{array}{l}0.54 \\
(0.542-0.544)\end{array}$ \\
\hline \multicolumn{9}{|l|}{ Overall function } \\
\hline \multicolumn{9}{|l|}{$60-69$ years } \\
\hline ADL disabilities & 3.5 & 0.83 & 0.88 & $\begin{array}{l}0.86 \\
(0.854-0.860)\end{array}$ & 3.2 & 0.66 & 0.83 & $\begin{array}{l}0.74 \\
(0.739-0.746)\end{array}$ \\
\hline
\end{tabular}


Table 2 Cutoff value of HGS, UWS, and overall function with self-reported ADL disabilities, IADL disabilities, upper-body limitations, lower-body limitations, and higher functional limitations by gender (Continued)

\begin{tabular}{|c|c|c|c|c|c|c|c|c|}
\hline & \multicolumn{4}{|c|}{ Male } & \multicolumn{4}{|c|}{ Female } \\
\hline & $\mathrm{CP}$ & Sn & Sp & AUC $(95 \% \mathrm{Cl})$ & $\mathrm{CP}$ & Sn & Sp & AUC $(95 \% \mathrm{Cl})$ \\
\hline IADL disabilities & 4.3 & 0.52 & 0.70 & $\begin{array}{l}0.61 \\
(0.609-0.611)\end{array}$ & 4.2 & 0.66 & 0.50 & $\begin{array}{l}0.58 \\
(0.582-0.583)\end{array}$ \\
\hline Upper-body limitations & 4.3 & 0.62 & 0.64 & $\begin{array}{l}0.63 \\
(0.630-0.632)\end{array}$ & 4.0 & 0.60 & 0.56 & $\begin{array}{l}0.58 \\
(0.579-0.580)\end{array}$ \\
\hline Lower-body limitations & 4.2 & 0.61 & 0.64 & $\begin{array}{l}0.63 \\
(0.628-0.630)\end{array}$ & 4.0 & 0.60 & 0.59 & $\begin{array}{l}0.59 \\
(0.594-0.595)\end{array}$ \\
\hline Higher functional limitations & 4.3 & 0.61 & 0.64 & $\begin{array}{l}0.63 \\
(0.624-0.627)\end{array}$ & 3.7 & 0.48 & 0.70 & $\begin{array}{l}0.59 \\
(0.593-0.595)\end{array}$ \\
\hline \multicolumn{9}{|l|}{ 70-79years } \\
\hline ADL disabilities & 2.9 & 0.77 & 0.84 & $\begin{array}{l}0.80 \\
(0.800-0.805)\end{array}$ & 3.0 & 0.68 & 0.71 & $\begin{array}{l}0.70 \\
(0.693-0.698)\end{array}$ \\
\hline IADL disabilities & 3.7 & 0.59 & 0.71 & $\begin{array}{l}0.65 \\
(0.653-0.655)\end{array}$ & 3.5 & 0.58 & 0.60 & $\begin{array}{l}0.59 \\
(0.585-0.588)\end{array}$ \\
\hline Upper-body limitations & 3.5 & 0.62 & 0.72 & $\begin{array}{l}0.67 \\
(0.664-0.666)\end{array}$ & 3.5 & 0.61 & 0.55 & $\begin{array}{l}0.58 \\
(0.577-0.579)\end{array}$ \\
\hline Lower-body limitations & 3.7 & 0.66 & 0.64 & $\begin{array}{l}0.65 \\
(0.648-0.651)\end{array}$ & 3.4 & 0.56 & 0.61 & $\begin{array}{l}0.59 \\
(0.585-0.587)\end{array}$ \\
\hline Higher functional limitations & 3.5 & 0.63 & 0.72 & $\begin{array}{l}0.67 \\
(0.673-0.675)\end{array}$ & 3.6 & 0.71 & 0.45 & $\begin{array}{l}0.58 \\
(0.579-0.581)\end{array}$ \\
\hline
\end{tabular}

$C P$ cutoff point, $S_{n}$ sensitivity, $S_{p}$ specificity, $A U C$ area under curve, $A D L$ activities of daily living, IADL instrumental activities of daily living

relationship with being functionally limited in each outcome of the physical performance tests. This was however not the case in the older female group when controlling for all confounders (model 3). UWS is therefore not a significant indicator for all functional restrictions except ADL disabilities, while HGS and overall function are not significant indicators for IADL disabilities and higher functional limitations, respectively.

\section{Discussion}

This analysis aimed to identify the validity of the suggested cutoff points of physical measures (HGS, UWS, and overall function) to predict functional limitations (i.e., ADL disabilities, IADL disabilities, upper-body limitations, lower-body limitations, and higher functional limitations). Our results show that the predictive power of the cutoff points of the three physical measures varied according to health outcomes and sex. For instance, the HGS cutoff points showed a significantly higher predictive power for men than for women. We also found that not all performance measurements were good indicators of functional limitations. We further found that overall function had more power to detect ADL disabilities than physical tests alone.

Some variations in the norms [36] and risk thresholds of performing tasks at different difficulty levels [21-23, 36] among older adults are also supported by our results. The mean value of UWS for elderly American and Italian community-dwellers ranges from 1.03 to $1.07 \mathrm{~m} / \mathrm{s}$, whereas usual walking speeds of 0.60 to $1.00 \mathrm{~m} / \mathrm{s}$ could be predictive of future risk factors for adverse health outcomes in various populations [28, 37-39]. For HGS, the mean maximum range was from 31.3 to $41.0 \mathrm{~kg}$ and 19.2 to $25.0 \mathrm{~kg}$ respectively, for older male and female adults in Western countries. HGS at $35 \mathrm{~kg}$ in men and $22 \mathrm{~kg}$ in women showed a risk of weakness [21] and HGS at 32 to $33 \mathrm{~kg}$ in men and 19 to $21 \mathrm{~kg}$ in women showed a risk of impaired mobility [22, 23, 36]. A comparison with our findings reveals that, when considering available cutoff values (AUC $\geq 60$ ), the cutoff points for UWS provided a value of less 0.8 . The HGS cutoff points showed a slightly lower value in the younger age group and an even lower value for $\mathrm{ADL}$ disabilities.

ADL disabilities in our study occur at the lowest values of each physical performance, which is consistent with the results of a previous study [40]. Young et al. (2010) showed that the mean value of UWS was the highest for older women unable to do heavy housework, followed by those unable to bathe, do shopping, walk up 10 steps, dress, and get out of bed. This is consistent with a recent study showing that the cutoff points were associated with outcomes [41] and is also confirmed by our own findings. Our findings suggest that the inability to perform tasks of daily living is more likely to increase with increasing weakness in muscular strength than IADL tasks or other functional limitations.

According to single physical measures in our study, the HGS test provided cutoff values $(A U C \geq 60$ ) for all 
Table 3 Odd ratios for ADL disabilities, IADL disabilities, upper-body limitations, lower-body limitations, and higher functional limitations according to HGS, UWS, and overall function by gender

\begin{tabular}{|c|c|c|c|c|c|c|}
\hline \multirow[t]{3}{*}{ Variable } & \multicolumn{3}{|l|}{ Male } & \multicolumn{3}{|l|}{ Female } \\
\hline & Model 1 & Model 2 & Model 3 & Model 1 & Model 2 & Model 3 \\
\hline & OR & OR & OR & OR & OR & OR \\
\hline \multicolumn{7}{|l|}{ Handgrip strength } \\
\hline \multicolumn{7}{|l|}{ 60-69 years } \\
\hline ADL disabilities & $17.25^{* * *}$ & $20.01 * * *$ & $20.48^{* * *}$ & $5.90^{* * *}$ & $6.70^{* * *}$ & $3.39^{*}$ \\
\hline IADL disabilities & $1.84^{* * *}$ & $1.77^{* * *}$ & $1.45^{* *}$ & $1.43^{* * *}$ & $1.73^{* * *}$ & $1.70^{* * *}$ \\
\hline Upper-body limitations & $2.85^{* * *}$ & $2.79^{* * *}$ & $2.69^{* * *}$ & $1.40^{*}$ & $1.61^{* * *}$ & $1.62^{* * *}$ \\
\hline Lower-body limitations & $2.33^{* * *}$ & $2.25^{* * *}$ & $2.19^{* * *}$ & $1.90^{* * *}$ & $2.15^{* * *}$ & $2.24^{* * *}$ \\
\hline Higher functional limitations & $2.34^{* * *}$ & $2.27^{* * *}$ & $2.34^{* * *}$ & $1.62^{* * *}$ & $1.85^{* * *}$ & $1.91^{* * *}$ \\
\hline \multicolumn{7}{|l|}{ 70-79years } \\
\hline ADL disabilities & $10.74^{* *}$ & $12.01^{* *}$ & $22.80^{* * *}$ & $3.05^{* * *}$ & $3.10^{* * *}$ & $2.59^{*}$ \\
\hline IADL disabilities & $2.26^{* * *}$ & $2.18^{* * *}$ & $2.35^{* *}$ & $2.01^{* * *}$ & $2.05^{* * *}$ & $1.75^{* *}$ \\
\hline Upper-body limitations & $3.41^{* * *}$ & $3.61^{* * *}$ & $3.60^{* * *}$ & $1.70^{* * *}$ & $1.86^{* * *}$ & $1.34^{*}$ \\
\hline Lower-body limitations & $2.12^{* * *}$ & $2.22^{* * *}$ & $1.93^{* * *}$ & $1.78^{* * *}$ & $1.89^{* * *}$ & $1.32^{*}$ \\
\hline Higher functional limitations & $2.13^{* * *}$ & $2.12^{* * *}$ & $2.65^{* * *}$ & $1.75^{* * *}$ & $1.84^{* * *}$ & 1.31 \\
\hline \multicolumn{7}{|l|}{ Usual walking speed } \\
\hline \multicolumn{7}{|l|}{ 60-69 years } \\
\hline ADL disabilities & $6.92^{* *}$ & $6.32^{* *}$ & $5.77^{*}$ & $5.66^{* * *}$ & $5.33^{* * *}$ & $21.77^{* * *}$ \\
\hline IADL disabilities & 1.33 & 1.17 & 1.08 & $1.77^{* * *}$ & $1.38^{* * *}$ & $1.35^{* *}$ \\
\hline Upper-body limitations & $1.72^{* *}$ & $1.80^{* * *}$ & $2.03^{* * *}$ & $2.17^{* * *}$ & $1.92^{* * *}$ & $2.07^{* * *}$ \\
\hline Lower-body limitations & $2.03^{* * *}$ & $2.15^{* * *}$ & $2.29^{* * *}$ & $2.45^{* * *}$ & $2.18^{* * *}$ & $2.21^{* * *}$ \\
\hline Higher functional limitations & $1.81^{*}$ & $1.88^{* * *}$ & $2.35^{* * *}$ & $2.46^{* * *}$ & $2.06^{* * *}$ & $2.31^{* * *}$ \\
\hline \multicolumn{7}{|l|}{ 70-79 years } \\
\hline ADL disabilities & $20.09^{* * *}$ & $29.67^{* * *}$ & $25.96^{* * *}$ & $4.80^{* * *}$ & $4.94^{* * *}$ & $2.45^{*}$ \\
\hline IADL disabilities & 1.12 & 1.14 & 1.05 & $1.95^{* * *}$ & $1.69^{* * *}$ & 1.32 \\
\hline Upper-body limitations & $2.81^{* * *}$ & $2.88^{* * *}$ & $2.78^{* * *}$ & $1.69^{* * *}$ & $1.57^{* * *}$ & 1.25 \\
\hline Lower-body limitations & $1.89^{* * *}$ & $1.94^{* * *}$ & $1.97^{* * *}$ & $1.55^{* * *}$ & $1.48^{* *}$ & 1.21 \\
\hline Higher functional limitations & $2.93^{* * *}$ & $2.96^{* * *}$ & $2.69^{* * *}$ & $1.63^{* *}$ & $1.54^{* *}$ & 1.29 \\
\hline \multicolumn{7}{|l|}{ Overall function } \\
\hline \multicolumn{7}{|l|}{ 60-69 years } \\
\hline ADL disabilities & $46.60^{* * *}$ & $51.62^{* * *}$ & $49.81^{* * *}$ & $8.01^{* * *}$ & $8.16^{* * *}$ & $8.56^{* * *}$ \\
\hline IADL disabilities & $1.91^{* * *}$ & $1.89^{* * *}$ & $1.80^{* * *}$ & $1.72^{* * *}$ & $1.76^{* * *}$ & $1.70^{* * *}$ \\
\hline Upper-body limitations & $2.64^{* * *}$ & $2.66^{* * *}$ & $2.77^{* * *}$ & $1.76^{* * *}$ & $1.87^{* * *}$ & $1.93^{* * *}$ \\
\hline Lower-body limitations & $2.59^{* * *}$ & $2.56^{* * *}$ & $2.71^{* * *}$ & $2.15^{* * *}$ & $2.22^{* * *}$ & $2.25^{* * *}$ \\
\hline Higher functional limitations & $2.73^{* * *}$ & $2.70^{* * *}$ & $3.29^{* * *}$ & $2.18^{* * *}$ & $2.29^{* * *}$ & $2.64^{* * *}$ \\
\hline \multicolumn{7}{|l|}{ 70-79years } \\
\hline ADL disabilities & $14.29 * * *$ & $14.48^{* * *}$ & $18.88^{* * *}$ & $4.04^{* * *}$ & $4.02^{* * *}$ & $3.15^{*}$ \\
\hline IADL disabilities & $1.58^{* *}$ & $1.71^{* * *}$ & $1.60^{* *}$ & $1.83^{* *}$ & $1.70^{* *}$ & 1.44 \\
\hline Upper-body limitations & $2.23^{* * *}$ & $2.20^{* * *}$ & $2.19^{* * *}$ & $2.02^{* * *}$ & $2.06^{* * *}$ & $1.58^{* *}$ \\
\hline Lower-body limitations & $1.70^{* *}$ & $1.73^{* * *}$ & $1.58^{* *}$ & $2.17^{* * *}$ & $2.23^{* * *}$ & $1.63^{* *}$ \\
\hline Higher functional limitations & $1.72^{* *}$ & $1.65^{* *}$ & $1.68^{* *}$ & $1.85^{* * *}$ & $1.83^{* * *}$ & $1.42^{*}$ \\
\hline
\end{tabular}

Notes: Model 1 adjusted for age, height, and weight; Model 2 adjusted for age, height, weight, education groups, and geographic region; Model 3 adjusted for age, height, weight, education groups, and geographic region, cognitive problems, diabetes, and hypertension; OR Odd ratio, $A D L$ activities of daily living, IADL instrumental activities of daily living

${ }^{*} p<0.05,{ }^{* *} p<0.01,{ }^{* * *} p<0.001$ 
functional limitations in both the younger and older age groups of elderly Thai men and for ADL disabilities in elderly Thai women. UWS provided cutoff values for ADL disabilities in elderly males and females of both age groups, upper-body and higher-body functional limitations in males aged 70 to 79 years, and lower-body and higher-body functional limitations in females aged 60 to 69. Moreover, these cutoff values were significantly associated with functional limitations, although potential confounding factors were controlled for. We also found that the combination of HGS and UWS tests as representative of overall function appeared to better differentiate between with- and without- ADL disabilities in both age groups and sexes than single physical performance measures. Our findings indicate that combined performance measures could increase the ability to predict ADL disabilities among elderly Thais. However, UWS was better to identify disabilities in the older Thai group.

The present study first addressed the cutoff values to assess functional limitations of performance-based measurements for two age groups of elderly Thai people from a nationwide representative sample. These cutoff points have important implications in terms of identifying the risk of disabilities in elderly Thais, which would place a heavy burden on both families and society with respect to healthcare cost and assistance needs. Early detection of disabilities provides the greatest advantages for direct preventive interventions. Nevertheless, as the present study is limited by its cross-sectional nature and health is a dynamic concept, we are unable to investigate the association between physical-based measurement and functional limitations over time. In addition, as the age range of the sample population is limited to between 60 and 79 years, Thais aged 80 years and above are not included. Further studies should assess the association between the changes in individual physical performance and functional limitations that include the oldest old Thais.

Moreover, AUC which was used in our study to measure the detection power of a diagnostic test, varied in performance according to the type of functional limitations in question, ranging from 0.53 to 0.86 , and was thus found not to be suitable for clinical use except to determine ADL disabilities [42]. Although previous studies suggested that the self-reporting approach including ADLs, IADLs, mobility performance, and objective physical performance tests could potentially predict health status $[2,19$, 20], the interview and examination procedures of the NHES IV of Thailand took place at local health centers, schools, or temples in the community, which may have been a problem for more severely disabled people. Therefore, further attempts to investigate physical performance scores in a clinical setting with a heterogeneous level of disability of Thai elderly people are needed to confirm our findings.

\section{Conclusions}

To sum up, the cutoff points of three measures of HGS, UWS, and overall function in our results varied according to the type of functional limitations and the sex of the subject. These values suggested that there is potential to distinguish men and women presenting a higher risk of $\mathrm{ADL}$ and other functional limitations (IADL disabilities, upper-body limitations, lower-body limitations, and higher functional limitations). However, as the AUC of the cutoffs of other functional limitations were relatively low, they should be considered with caution. Interestingly, overall function is more useful than HGS and UWS alone for detecting ADL disabilities in Thai elderly people. Future studies should examine the cutoff points in a clinical setting with a heterogeneous level of disabilities of elderly Thais and include the results in the next NHES survey.

\section{Additional file}

Additional file 1: Figure S1-S5. (DOCX $27715 \mathrm{~kb}$ )

\section{Abbreviations}

ADLs: Activities of daily living; AUCs: Areas under the curve; FPG: Fasting plasma glucose; HGS: Handgrip strength; IADLs: Instrumental activities of daily living; NHES IV: National health examination surveys of Thailand; ROC: Receiver operating characteristic; UWS: Usual walking speed

\section{Acknowledgements}

The Thai National Health Examination Survey IV (NHES IV) was conducted by the National Health Examination Survey Office of the Health Systems Research Institute of Thailand. The NHES IV study group includes: National Health Examination Survey Office: Wichai Aekplakorn, Rungkarn Inthawong, Jiraluck Nonthaluck, Supornsak Tipsukum, Yawarat Porrapakkham; Northern region: Suwat Chariyalertsak, Kanittha Thaikla (Chiang Mai University), Wongsa Laohasiriwong, Wanlop Jaidee, Sutthinan Srathonghon, Ratana Phanphanit, Jiraporn Suwanteerangkul, Kriangkai Srithanaviboonchai; North Eastern Region: Pattapong Kessomboon, Somdej Pinitsoontorn, Piyathida Kuhirunyaratn, Sauwanan Bumrerraj, Amornrat Rattanasiri, Suchad Paileeklee, Bangornsri Jindawong, Napaporn Krusun, Weerapong Seeupalat (Khon Kaen University); Southern region: Virasakdi Chongsuvivatwong, Rassamee Sangthong, Mafausis Dueravee (Prince of Songkla University); Central Region: Surasak Taneepanichskul, Somrat Lertmaharit, Vilai Chinveschakitvanich, Onuma Zongram, Nuchanad Hounnaklang, Sukarin Wimuktayon (Chulalongkorn University); Bangkok Region: Panwadee Putwatana, Chalermsri Nuntawan, Karn Chaladthanyagid (Mahidol University). The NHES IV was supported financially by the Health System Research Institute; Bureau of Policy and Strategy, Ministry of Public Health; Thai Health Promotion Foundation; National Health Security Office, Thailand.

The authors especially wish to thank Dr. Wichai Aekplakorn at the Faculty of Medicine at Mahidol University for his help in commenting on the manuscript.

\section{Funding}

The work was supported by the European Research Council under the European Union's Seventh Framework Programme (FP7/2007-2013)/ ERC under Grant ERC2012-AdG 323947-Re-Ageing. The funder had no role in the design and execution of the study, in the collection, analysis, and interpretation of the data, or the preparation, review, and approval of the manuscript.

\section{Availability of data and materials}

The data that support the findings of this study are available from the National Health Examination Survey Office of the Health Systems Research Institute of 
Thailand, but restrictions apply to the availability of these data, which were used under license for the current study, and so are not publicly available. Data are however available from the authors upon reasonable request and with the permission of the National Health Examination Survey Office.

\section{Authors' contributions}

DW jointly conceived the study with OP, designed the study, interpreted and discussed the results, and prepared the manuscript. OP collected and analyzed the data and wrote the manuscript. DW supervised its analyses and reviewed/edited the manuscript. All authors have read and approved the manuscript.

\section{Ethics approval and consent to participate}

Ethical approval was provided by the Ethical Review Committee for Research in Human Subjects of the Thai Ministry of Public Health. None of the authors had access to information that would enable the identification of individual participants. Participants provided written informed consent.

\section{Consent for publication}

Not applicable.

\section{Competing interests}

The authors declare that they have no competing interests.

\section{Publisher's Note}

Springer Nature remains neutral with regard to jurisdictional claims in published maps and institutional affiliations.

\section{Author details}

${ }^{1}$ College of Population Studies, Chulalongkorn University, Bangkok 10330, Thailand. ${ }^{2}$ Wittgenstein Centre for Demography and Global Human Capital (IIASA, VID/OEAW, WU), International Institute for Applied Systems Analysis (IIASA), 2361 Laxenburg, Austria. ${ }^{3}$ Health Economics and Policy Division, Vienna University of Economics and Business, Welthandelsplatz 1, 1020 Vienna, Austria.

\section{Received: 9 May 2018 Accepted: 26 February 2019}

Published online: 05 March 2019

\section{References}

1. Knodel J, Teerawichitchainan B, Prachuabmoh V, Pothisiri W. The situation of Thailand's older population: an update based on the 2014 survey of older persons in Thailand. Research Collection School of Social Sciences. 2015; http://ink.library.smu.edu.sg/soss_research/1948.

2. Cruz-Jentoft AJ, Baeyens JP, Bauer JM, Boirie Y, Cederholm T, Landi F, et al. Sarcopenia: European consensus on definition and diagnosis: report of the European working group on sarcopenia in older people. Age Ageing. 2010; 39:412-23.

3. Guadalupe-Grau A, Carnicero JA, Gomez-Cabello A, Gutierrez Avila G, Humanes S, Alegre LM. Association of regional muscle strength with mortality and hospitalisation in older people. Age Ageing. 2015;44. https:// doi.org/10.1093/ageing/afv080.

4. Chen P-J, Lin M-H, Peng L-N, Liu C-L, Chang C-W, Lin Y-T, et al. Predicting cause-specific mortality of older men living in the veterans home by handgrip strength and walking speed: a 3-year, prospective cohort study in Taiwan. J Am Med Assoc. 2012;13:517-21.

5. Giampaoli S, Ferrucci L, Cecchi F, Noce CL, Poce A, Dima F, et al. Hand-grip strength predicts incident disability in non-disabled older men. Age Ageing. 1999;28:283-8

6. Blain H, Carriere I, Sourial N, Berard C, Favier F, Colvez A, et al. Balance and walking speed predict subsequent 8-year mortality independently of current and intermediate events in well-functioning women aged 75 years and older. J Nutr Health Aging. 2010;14:595-600.

7. Koopman JJE, van Bodegom D, van Heemst D, Westendorp RGJ. Handgrip strength, ageing and mortality in rural Africa. Age Ageing. 2015;44:465-70.

8. Ling CHY, Taekema D, Craen AJM de, Gussekloo J, Westendorp RGJ, Maier $A B$. Handgrip strength and mortality in the oldest old population: the Leiden 85-plus study. Can Med Assoc J 2010;182:429-435.

9. Gale CR, Martyn CN, Cooper C, Sayer AA. Grip strength, body composition, and mortality. Int J Epidemiol. 2007;36:228-35.
10. Rantanen T, Volpato S, Luigi Ferrucci M, Eino Heikkinen M, Fried LP, Guralnik JM. Handgrip Strength and cause-specific and Total mortality in older disabled women: exploring the mechanism. J Am Geriatr Soc. 2003;51:636-41.

11. Sasaki H, Kasagi F, Yamada M, Fujita S. Grip Strength predicts cause-specific mortality in middle-aged and elderly persons. Am J Med. 2007;120:337-42.

12. Snih SA, Markides KS, Ray L, Ostir GV, Goodwin JS. Handgrip strength and mortality in older Mexican Americans. J Am Geriatr Soc. 2002;50:1250-6.

13. Lyons JG, Ensrud KE, Schousboe JT, McCulloch CE, Taylor BC, Heeren TC, et al. Slow gait speed and risk of long-term nursing home residence in older women, adjusting for competing risk of mortality: results from the study of osteoporotic fractures. J Am Geriatr Soc. 2016;64:2522-7.

14. Guralnik JM, Simonsick EM, Ferrucci L, Glynn RJ, Berkman LF, Blazer DG, et al. A short physical performance battery assessing lower extremity function: association with self-reported disability and prediction of mortality and nursing home admission. J Gerontol. 1994:49:M85-94.

15. Studenski S, Perera S, Patel K, a. Gait speed and survival in older adults. JAMA. 2011:305:50-8.

16. Albert SM, Bear-Lehman J, Anderson SJ. Declines in mobility and changes in performance in the instrumental activities of daily living among mildly disabled community-dwelling older adults. J Gerontol A Biol Sci Med Sci. 2015;70:71-7.

17. Veronese N, Stubbs B, Trevisan C, Bolzetta F, De Rui M, Solmi M, et al. What physical performance measures predict incident cognitive decline among intact older adults? A 4.4 year follow up study. Exp Gerontol. 2016;81:110-8.

18. Schaap LA, Fox B, Henwood $T$, Bruyère $O$, Reginster J-Y, Beaudart $C$, et al. Research paper: grip strength measurement: towards a standardized approach in sarcopenia research and practice. Eur Geriatr Med. 2016;7:247-55.

19. Castell M-V, Sánchez M, Julián R, Queipo R, Martín S, Otero Á. Frailty prevalence and slow walking speed in persons age 65 and older: implications for primary care. BMC Fam Pract. 2013:14:86.

20. Bahat G, Tufan A, Tufan F, Kilic C, Akpinar TS, Kose M, et al. Cut-off points to identify sarcopenia according to European working group on sarcopenia in older people (EWGSOP) definition. Clin Nutr. 2016;35:1557-63.

21. Duchowny KA, Peterson MD, Research Article CPJ. Cut points for clinical muscle weakness among older Americans. Am J Prev Med. 2017; https:// www.ncbi.nlm.nih.gov/pmc/articles/PMC5497994/.

22. Lauretani F, Russo CR, Bandinelli S, Bartali B, Cavazzini C, Di lorio A, et al. Age-associated changes in skeletal muscles and their effect on mobility: an operational diagnosis of sarcopenia. J Appl Physiol. 2003;95:1851.

23. Sallinen J, Stenholm S, Rantanen T, Heliövaara M, Sainio P, Koskinen S. Hand-grip strength cut points to screen older persons at risk for mobility limitation. J Am Geriatr Soc. 2010;58:1721-6.

24. Strength YAMG. Multimorbidity, and disability. Dissertation. In: Western Michigan University; 2013. http://scholarworks.wmich.edu/dissertations/227.

25. Yorke AM, Curtis AB, Shoemaker M, Vangsnes E. Grip Strength values stratified by age, gender, and chronic disease status in adults aged 50 years and older. J Geriatr Phys Ther. 2015;38:115-21.

26. Seino S, Kim M, Yabushita N, Nemoto M, Jung S, Osuka Y, et al. Is a composite score of physical performance measures more useful than usual gait speed alone in assessing functional status? Arch Gerontol Geriatr. 2012;55:392-8.

27. Seino S, Yabushita N, Kim M, Nemoto M, Jung S, Osuka Y, et al. Comparison of a combination of upper extremity performance measures and usual gait speed alone for discriminating upper extremity functional limitation and disability in older women. Arch Gerontol Geriatr. 2012;55:486-91.

28. Guralnik JM, Ferruci L, Pieper CF, Leveille SG, Markides KS, Ostir GV. Lower extremity function and subsequent disability: consistency across studies, predictive models, and value of gait speed alone compared with the short physical performance battery. J Geront Biol Sci Med Sci. 2000;55. https://doi. org/10.1093/gerona/55.4.M221.

29. Chan KS, Kasper JD, Brandt J, Pezzin LE. Measurement equivalence in ADL and IADL difficulty across international surveys of aging: findings from the HRS, SHARE, and ELSA.J Gerontol B Psychol Sci Soc Sci. 2012:67B:121-32.

30. Apinonkul B, Soonthorndhada K, Vapattanawong P, Aekplakorn W, Jagger C Gender differences in health expectancies across the disablement process among older Thais. PLoS One. 2015;10:e0121310.

31. Crimmins EM, Kim JK, Langa KM, Weir DR. Assessment of cognition using surveys and neuropsychological assessment: the health and retirement study and the aging, demographics, and memory study. J Gerontol B Psychol Sci Soc Sci 2011;66 Suppl 1 Suppl 1:i162-i171.

32. Hajian-Tilaki K. Receiver operating characteristic (ROC) curve analysis for medical diagnostic test evaluation. Casp J Intern Med. 2013;4:627-35. 
33. DeLong ER, DeLong DM, Clarke-Pearson DL. Comparing the areas under two or more correlated receiver operating characteristic curves: a nonparametric approach. Biometrics. 1988;44:837-45.

34. Hanley JA, McNeil BJ. A method of comparing the areas under receiver operating characteristic curves derived from the same cases. Radiology. 1983;148:839-43.

35. Dong R, Wang X, Guo Q, Wang J, Zhang W, Shen S, et al. Clinical relevance of different handgrip Strength indexes and mobility limitation in the elderly adults. J Gerontol A Biol Sci Med Sci. 2016;71:96.

36. Mendes J, Amaral TF, Borges N, Santos A, Padrão P, Moreira P, et al. Handgrip strength values of Portuguese older adults: a population based study. BMC Geriatr. 2017;17:191

37. Studenski S, Perera S, Wallace D, Chandler JM, Duncan PW, Rooney E, et al. Physical performance measures in the clinical setting. J Am Geriatr Soc. 2003;51:314-22.

38. Cesari M, Kritchevsky SB, Penninx BWHJ, Nicklas BJ, Simonsick EM, Newman $A B$, et al. Prognostic value of usual gait speed in well-functioning older people-results from the health, aging and body composition study. J Am Geriatr Soc. 2005;53:1675-80.

39. Hong S, Kim S, Yoo J, Kim BS, Choi HR, Choi SE, et al. Slower gait speed predicts decline in instrumental activities of daily living in communitydwelling elderly: 3 -year prospective finding from living profiles of older people survey in Korea. J Clin Gerontol Geriatr. 2016;7:141-5.

40. Young Y, Boyd CM, Guralnik JM, Bandeen-Roche K, Fried LP. Does selfreported function correspond to objective measures of functional impairment? J Am Med Dir Assoc. 2010;11:645-53.

41. Middleton A, Fritz SL, Lusardi M. Walking speed: the functional vital sign. J Aging Phys Act. 2015;23:314-22.

42. Fan J, Upadhye S, Worster A. Understanding receiver operating characteristic (ROC) curves. Can J Emerg Med. 2006:8:19-20.

Ready to submit your research? Choose BMC and benefit from:

- fast, convenient online submission

- thorough peer review by experienced researchers in your field

- rapid publication on acceptance

- support for research data, including large and complex data types

- gold Open Access which fosters wider collaboration and increased citations

- maximum visibility for your research: over $100 \mathrm{M}$ website views per year

At $\mathrm{BMC}$, research is always in progress.

Learn more biomedcentral.com/submissions 